established these facts: The child, a girl of twelve, had been exposed to the infection of variola fourteen days previously, when a younger brother had died of that disease. The girl had been vaccinated eight days before coming to the hospital. The small-pox had, therefore, had a week's start of the vaccinia. The variolous eruption was considerably modified, the pustules being much less numerous and smaller than usual. The temperature, however, was high, being $104^{\circ} \mathrm{F}$, and the child was acutely ill, with very severe sore throat; this case also was accepted by the Asylums Board without demur, so that the diagnosis may be considered as established.

\title{
Case of Scurvy with Well-Marked Purpura.
}

By J. Clark Wilson, M.D.

Cases of scurvy are now fortunately sufficiently rare in this country to be worthy of interest. The following case is especially interesting from the unusually severe purpuric symptoms with which it was associated, and from the apparent failure at first of lemons to ward off the condition.

W. P., a boy aged 13, the son of a coachman, and living in a mews, was first seen on January 14th, suffering from scurvy. $\mathrm{He}$ had had rheumatism at the age of 5 , but not since, and had never previously to the onset of the scurvy had a skin-eruption of any kind. At Christmas the boy had become suddenly feverish and out of sorts, and felt very ill. He was kept in bed for three days. On getting up he complained that his teeth all felt loose; his breath was offensive, and his gums bled at the slightest touch, and his clothes were always marked with blood. His mother noticed that there were slight gaps between the gums and several of the teeth. At the same time he was paler than usual, and the least exertion tired him ; his appetite was poor, and he was generally out of sorts.

On January 2nd there was first noticed an eruption of purple scattered spots, most marked on the arms and hands, but also, though to a less extent, on the legs. Three large lesions like bruises-though there had been no injury to eause them-appeared at the same time on the forearms.

When first seen on January 14th, scattered patechiæ, about the 
size of a large pin's head, were present on the arms and legs, as well as three large vibices with a purplish centre fading off to green and yellow, and projecting well above the level of the skin of the arm. The gums were spongy and bluish, and bled on the slightest touch. The boy was pallid and had a small and weak pulse. The nature of the condition was more clearly shown by the fact that the patient had always had a marked dislike to vegetables. Potatoes he would sometimes take, but never green vegetables. On the other hand he had for several years past been very fond of lemons, and latterly had taken them on every possible occasion-on an average two or three a week.

He was put on green food and two lemons a day, and at once the gums and general condition began to improve. But on the 17th, the shoulders, upper half of the back and chest became covered by a mottled pink rash. This was almost symmetrical, and was circinate in arrangement. It did not disappear on pressure. In many places there was a deepening of the pink tint at the margins to a scarlet colour. This soon began to fade, and by the 22 nd was all gone, except for the merest traces here and there. But in the meantime a similar condition appeared on the abdomen, lower part of the back, and gluteal region, the circinate arrangement not being so marked, but the symmetry and the heightening of colour at the margins were more so. The mottling also left much smaller surfaces uninvolved, the only one of any size being a circle with a diameter of about $\mathbf{2}$ inches, immediately behind the great trochanter on each side.

Some slight irritation was complained of while the rash was first coming out on the back, but none after it was fully developed.

By the 25th the eruption had disappeared from the back and gluteal region, except for one or two of the deeper-coloured margins ; but not from the abdomen, though it was fainter there. The original petechiø on the arms and legs, and vibices, though still visible, were also fast disappearing. The gums were quite healthy, except for a small patch in contact with two of the teeth, the bleeding was very slight, and the general condition also was very much improved. 